\title{
Determinación de la capacidad antioxidante de la Passiflora ligularis
} (granadilla)

\author{
Emilio Guija, Luzmila Troncoso, Gisela Oliveira, Mercedes Soberón, Juana Flores, Marco Núñez
}

Centro de Investigación de Bioquímica y Nutrición, Facultad de Medicina, UNMSM

Objetivos: Determinar la actividad antioxidante de la Passiflora ligularis.

Diseño: Descriptivo, observacional.

Institución: Centro de Investigación de Bioquímica y Nutrición, Facultad de Medicina, UNMSM.

Material biológico: Passiflora ligularis (granadilla).

Intervenciones: Se separó la parte comestible de la fruta, la que fue homogenizada con agua destilada, centrifugada y el sobrenadante usado para realizar las diferentes determinaciones analíticas, tales como, los niveles de compuestos antioxidantes y la capacidad para captar el radical DPPH, para cuyo propósito de utilizó concentraciones diferentes de la fruta.

Principales medidas de resultados: Determinación de compuestos antioxidantes, evaluación de la capacidad antioxidante, capacidad captadora del radical DPPH.

Resultados: La Passiflora ligularis mostró un valor de polifenoles de $28,7 \mathrm{mg}$ eq de ácido gálico/100 mL de jugo, flavonoides $1,66 \mathrm{mg}$ eq de catequina/100 mL de jugo, vitamina C $20 \mathrm{mg} / 100 \mathrm{~mL}$ de jugo, FRAP $0,37 \mathrm{mmoles}$ de Fe-Il/100 $\mathrm{mL}$ de jugo y DPPH IC50 0,011 mg/mL.

Conclusiones: La actividad antioxidante de la Passiflora ligularis fue moderada, comparada con otras frutas, que mostraron valores más elevados.

Palabras clave: Pasiflora ligularis, granadilla, antioxidante, FRAP, DPPH.

\section{Efecto del tratamiento térmico sobre la capacidad antioxidante total y contenido de polifenoles de brócoli, pimiento y tomate}

\author{
Gisela Oliveira, Luzmila Troncoso, Emilio Guija, Marco Núñez, Juana Flores
}

Centro de Investigación de Bioquímica y Nutrición, Facultad de Medicina, UNMSM

Objetivos: 1) Determinar la capacidad antioxidante total de brócoli, pimiento y tomate frescos. 2) Determinar el efecto térmico sobre la capacidad antioxidante total de brócoli, pimiento y tomate. 3) Determinar el efecto térmico sobre el contenido de polifenoles de brócoli, pimiento y tomate.

Diseño: Estudio analítico, experimental, prospectivo.

Institución: Centro de Investigación de Bioquímica y Nutrición, Facultad de Medicina, UNMSM.

Material biológico: Frutos frescos y maduros de brócoli, pimiento y tomate.

Intervenciones: Se trató un extracto metanólico 2:28 de brócoli, pimiento y tomate con el radical libre DPPH y se leyó en el espectrofotómetro a $517 \mathrm{~nm}$, para obtener el IC50. Para la determinación de polifenoles, se trabajó con un extracto acuoso usando el reactivo Folin Ciocalteau; se leyó en el espectrofotómetro a $765 \mathrm{~nm}$.

Principales medidas de resultados: Capacidad antioxidante total y contenido de polifenoles.

Resultados: El IC50 obtenido después de someter a tratamiento térmico al brócoli, pimiento y tomate fue, respectivamente: a) ebullición $I C 50=2,12 \mathrm{mg} / \mathrm{mL}, 3,46 \mathrm{mg} / \mathrm{mL}$ y $4,37 \mathrm{mg} / \mathrm{mL} ;$ b) vapor $I C 50=1,93 \mathrm{mg} / \mathrm{mL}, 2,94 \mathrm{mg} / \mathrm{mL}$ y $3,54 \mathrm{mg} / \mathrm{mL} ; \mathrm{c}$ ) microondas $1,25 \mathrm{mg} / \mathrm{mL}, 2,04 \mathrm{mg} / \mathrm{mL}$ y 2,64 mg/mL. El contenido de polifenoles: a) ebullición $27 \mathrm{mg}, 25 \mathrm{mg}$ y $5,3 \mathrm{mg}$; b) vapor $13 \mathrm{mg}, 5 \mathrm{mg}$ y $4 \mathrm{mg}$; y, c) microondas $12 \mathrm{mg}, 4 \mathrm{mg}$ y $2 \mathrm{mg}$, respectivamente.

Conclusiones: El tratamiento térmico produjo en brócoli, pimiento y tomate disminución de la capacidad antioxidante total y del contenido de polifenoles.

Palabras clave: Antioxidante, DPPH, polifenoles, brócoli, pimiento, tomate, tratamiento térmico. 